\title{
BMJ Open Association between district-level perceived safety and self-rated health: a multilevel study in Seoul, South Korea
}

\author{
Seung-Sup Kim, ${ }^{1,2,3,4}$ Jaesung Choi, ${ }^{5}$ Kisoo Park, ${ }^{4}$ Yeonseung Chung, ${ }^{6}$ \\ Sangjo Park, ${ }^{7}$ Jongho $\mathrm{Heo}^{8}$
}

To cite: Kim S-S, Choi J, Park K, et al. Association between district-level perceived safety and selfrated health: a multilevel study in Seoul, South Korea. BMJ Open 2014;4:e004695. doi:10.1136/bmjopen-2013004695

- Prepublication history for this paper is available online. To view these files please visit the journal online (http://dx.doi.org/10.1136/ bmjopen-2013-004695).

Received 16 December 2013 Revised 24 June 2014 Accepted 3 July 2014

CrossMark

For numbered affiliations see end of article.

Correspondence to

Jongho Heo;

joheo@ucsd.edu

\section{ABSTRACT}

Objectives: Several studies have reported the relationship between residents' perceived neighbourhood safety and their health outcomes. However, those studies suffered from unreliability of neighbourhood safety measure and potential residual confounding related to crime rates. In this study, using multilevel analysis to account for the hierarchical structure of the data, we examined associations between district-level perceived safety and self-rated health after adjusting for potential confounders including the district-level crime rate.

Design: Cross-sectional study.

Setting: We used the first wave of Seoul Welfare Panel Study, which has 7761 individuals from 3665 households in 25 administrative districts in Seoul, South Korea. District-level perceived safety was obtained by aggregating responses from the residents that are representative samples for each administrative district in Seoul. To examine an association between district-level safety and residents' self-rated health, we used mixed effect logistic regression.

Results: Our results showed that higher district-level perceived safety, an aggregated measure of district residents' responses towards neighbourhood safety, was significantly associated with poor self-rated health after controlling for sex, age, education level, job status, marital status and household income ( $\mathrm{OR}=0.87$, $95 \% \mathrm{Cl} 0.78$ to 0.97$)$. Furthermore, this association was still robust when we additionally adjusted for the district-level crime rate $(\mathrm{OR}=0.86,95 \% \mathrm{Cl} 0.77$ to 0.95).

Conclusions: Our study highlights the importance of improving neighbourhood perceived safety to enhance residents' health.

\section{INTRODUCTION}

Crime is one of the major problems in many metropolitan areas across countries. Although city crime rates have dropped globally since the mid-1990s, ${ }^{1}$ there are still large variations and dramatic fluctuations across cities. ${ }^{2}$ Past criminological studies revealed that variations in crime rates were

\section{Strengths and limitations of this study}

- A multilevel analytic frame was used to examine the association between district-level perceived safety and residents' self-rated health using a representative sample of metropolis, Seoul, South Korea.

- We succeed in adjusting for potential confounders such as the district-level crime rate in our analytic model, which past studies have failed.

- Causal relationships cannot be inferred from the cross-sectional data of this study.

explained by characteristics of metropolitan areas, such as population size, ethnic heterogeneity, geographic mobility, economic segregation, unemployment rate, poverty level and degree of social integration and control. ${ }^{2-4}$ Thus, many governments have made great efforts to reduce the crime rates especially in metropolitan areas by intervening in those characteristics to ensure the safety of their residents.

Safety from crime is not only an essential human need in daily life, but also a prerequisite to human health. ${ }^{5}$ A body of past studies has reported the relationship between residents' perceptions of neighbourhood safety and their health outcomes. ${ }^{6}{ }^{7}$ For example, one UK survey with 407 adults reported that fear of crime was significantly associated with self-rated health and mental well-being. ${ }^{8}$ Ziersch et $a l^{9}$ showed that perceived neighbourhood safety was related to physical and mental health among 2400 residents in western suburbs of Adelaide, Australia.

However, these earlier studies suffer from the following limitations. First, most of the previous studies used individual-level neighbourhood perceived safety as an exposure variable, which could be influenced by several factors such as the prior individual experience of victimisation or individual health conditions other than neighbourhood-level safety. ${ }^{10}{ }^{11}$ 
This could be particularly a critical issue in previous crosssectional studies because of the potential reverse causation, meaning that the sick people are more likely to perceive their neighbourhood as unsafe. ${ }^{7}{ }^{12}$ The second limitation is a lack of representativeness of samples within the operationalised definition of neighbourhood. Few studies had enough sample size or the sample size within neighbourhood to be representative of each neighbourhood. ${ }^{6} 8{ }^{13}$ Unless the responses are obtained from a representative sample of participants within each neighbourhood, aggregated perceived neighbourhood measures can potentially be prone to measurement errors. The final limitation is that previous studies did not adjust for the district-level crime rate as a potential confounder although the crime rate has been reported to influence perception of neighbourhood safety as well as residents' health outcomes.

In this study, we assessed the district-level perceived safety, which was obtained by aggregating responses from the residents that are representative samples for each administrative district in Seoul, the capital of South Korea. Then, using multilevel analysis to account for the hierarchical structure of the data, we examined the association between district-level perceived safety and selfrated health after adjusting for potential confounders including the district-level crime rate.

\section{METHODS}

\section{Study population}

Data were obtained from the Seoul Welfare Panel Study (SWPS), which tracked a representative sample of households residing in 25 administrative districts in Seoul, South Korea. The SWPS was launched in 2008 by the Seoul Welfare Foundation. The first wave of the survey was conducted in 2008 and its supplementary survey targeting the low-income households was implemented in 2009. The SWPS was suspended after the second wave of the survey was conducted in September 2010. The survey employed a two-stage stratified cluster sampling approach where a representative sample of census tracts for each district was first drawn, and then households were randomly selected within those sampled census tracts at the baseline. A household representative answered the household survey and all members of a household whose age is 15 or older were interviewed. A total of 7761 individuals completed the interviews in wave 1. The SWPS has been publicly released (www. welfare.seoul.kr). Because all respondents answered on questionnaire items we used in this study, we were able to conduct our analyses based on the entire sample participated in the first wave of SWPS without listwise deletion or missing value imputation for handling missing data. The final sample used in the data analysis of this research consists of 7761 individuals from 3665 households from 25 administrative districts in Seoul. The number of households in each district was 146.6 on average, ranging from 108 to 198 . This research received
Institutional Review Board exemption from the Division of Research Affairs at the San Diego State University.

\section{Exposure: district-level perceived safety}

District-level perceived safety was assessed through the household survey using a question about how much a household representative agrees with the following statement: "my current residential environment is unsafe." Respondents answered in a five level ordinal scale from 'strongly agree' (coded as 1) to 'strongly disagree' (coded as 5). The answer was then dichotomised into 'unsafe' (coded as 0) for the response, 1 and 2 and 'safe' (coded as 1) for the response, 3-5. The binary responses from household representatives were aggregated to calculate administrative district-level perceived neighbourhood safety by taking a weighted average of household-specific perceived safety within each district with the household size used as weight. Such aggregation results in that the district-level perceived neighbourhood safety is essentially the sample proportion of individuals who answered 'safe' within each district.

\section{Outcome: poor self-rated health}

Poor self-rated health was assessed through the individual interview using the question 'how would you rate your overall health?' This question is on the ordinal level, ranging from 'very good' (coded as 1) to 'very poor' (coded as 5). The response was then dichotomised into 'good health' (coded as 0) for the response, 1-3 and 'poor health' (coded as 1) for the response, 4 and 5. Although self-rated health cannot assess multidimensional aspects of health conditions, it is known to be a reliable predictor of life expectancy after adjusting for other health indicators. ${ }^{14}$

\section{Covariates}

We included several confounders in the data analysis. For individual-level confounders, we have sex, age group (15-19, 20-29, 30-39, 40-49, 50-59, 60-69 and 70 or more), education level (elementary school or less, junior high school, high school, college graduate, university graduate and graduate school or more), marital status (married or cohabiting vs others) and job status (employed vs unemployed), household income with six categories (1 $000000 \mathrm{KRW}$ or less; $1010000-2000000$ KRW; $2010000-3000000 \quad$ KRW; $3010000-4000$ 000 KRW; $4010000-5000000$ KRW; and above $5000000 \mathrm{KRW})$ and individual perception of district safety (unsafe vs safe). Because neighbourhood safety was assessed solely from the household survey, we assigned the value of perceived neighbourhood safety measured from each household representative to all members of the household.

We considered the district-level crime rate as a potential covariate at the district level because it can influence residents' health as well as perceived safety. District-level crime rates for each of the 25 administrative districts $(' \mathrm{Gu}$ ') in Seoul were collected from the 'analytical 
report on crimes, 2008' that was published by supreme prosecutors' office in South Korea. ${ }^{15}$ The district-level crime rate was calculated by dividing the total number of crimes by the total number of residents in each district (expressed in the total number of crimes in 2008/ population in $2008 * 100)$. Using an identifier for each administrative district in the SWPS, we linked the official crime rate of each administrative district to our final dataset of the SWPS.

\section{Data analysis}

Mixed effect logistic regression was used to investigate the association between district-level perceived safety and self-rated health. Because of the hierarchical structure in our data (ie, individuals are nested in households, which in turn are nested in districts), within-household and within-district correlations were incorporated using household-specific and districtspecific random intercepts. We made stepwise adjustments of potential confounders in the data analysis. First, we adjusted for potential confounders including sex, age, education level, job status, marital status and household income. Second, we additionally adjusted for the district-level crime rate. Finally, we examined the association after adjusting for individual perception of district safety in addition to all of the previously mentioned confounders. All of the confounders were included as categorical variables, and the district-level perceived safety was included after standardisation for simple interpretation in the model. All computations were performed using the R statistical software.

\section{RESULTS}

Table 1 presents the distribution of the study population and the prevalence of poor self-rated health by each of the individual-level, household-level and district-level characteristics. Overall, poor self-rated health was reported at $20.9 \%$ (1620 of 7761 participants). The proportion was higher for women and showed an increasing pattern with age. Higher prevalence of poor self-rated health were observed for participants with lower education levels. The unemployed and people living in an unsafe neighbourhood exhibited higher prevalence of poor self-rated health than the employed and those living in a safe neighbourhood. The household income was fairly equally distributed in the SWPS. As to the district-level perceived safety and crime rate, given the overall mean of each variable, the relative size of each SD shows that there were considerable variations among the 25 districts.

District-level perceived safety was significantly associated with poor self-rated health while different sets of confounders being step-wisely adjusted (Table 2). Living in a district where its safety level is $1 \mathrm{SD}(0.08)$ higher resulted in $13 \%$ lower odds of reporting self-rated poor health status $(\mathrm{OR}=0.87,95 \%$ CI 0.78 to 0.97$)$ after adjusting for sex, age, education level, job status, marital status and household income. When we additionally adjusted for the district-level crime rate, this association was slightly attenuated but still significant $(\mathrm{OR}=0.86$, $95 \%$ CI 0.77 to 0.95 ). When we adjusted for individual perception of district safety in addition to previously mentioned potential confounders, the magnitude of this association remained significant $(\mathrm{OR}=0.86,95 \%$ CI 0.77 to 0.96$)$.

\section{DISCUSSION}

Evidence from our study indicated that district-level perceived safety, which was assessed by aggregating responses from residents in each district, was significantly associated with poor self-rated health even after controlling for demographic information, socioeconomic status (SES) and district-level crime rate. Notably, this association was robust also when we additionally adjusted for individual perception of district safety.

Our findings are in line with previous research that showed association between perceived neighbourhood safety and health outcomes. Past studies have also reported that residents who perceived that their neighbourhood had more severe problems were more likely to experience greater anxiety, stress and depression. ${ }^{6} 16$ The studies, which sampled women, children and the elderly, also provided consistent evidence of a relationship between perceived crime risk and physical health. ${ }^{7} 13$

In this study, district-level crime rate was not associated with self-rated health in the fully adjusted model. Furthermore, our post-hoc analysis showed that there was no statistically significant relationship between district crime rate and residents' self-rated health regardless of adjustment of confounders, although the district-level crime rate could have a major influence on district-level perceived safety. This finding is different from past studies that reported a significant relationship between district crime rate and residents' health such as coronary heart disease $^{17}$ and low birth weight. ${ }^{18}$

The differential association between district-level perceived safety and crime rate in relation to self-rated health could be explained in three ways. First, mass media may increase individual-level perceived neighbourhood insecurity regardless of their neighbourhood crime rates, especially when they reported the crime in ways of exaggeration. ${ }^{19} 20$ The mass media tend to emphasise criminal stories which can draw attention from the audience. ${ }^{21}$ Previous studies called this phenomenon the 'cultivation effect' meaning that exposure to the world of television cultivates exaggerated perceptions of viewers and magnifies viewers' fear about crime. $^{22}$ The residents who watched news about neighbourhood crimes are more likely to perceive their neighbourhood as more vulnerable regions to crime regardless of the regional crime rate. ${ }^{20}$

Second, different types of crimes would have different effects on the perceived risk or fear of crime. For example, murder, rape and personal theft may have 
Table 1 Distribution of study population and prevalence of poor self-rated health by key covariates among 7761 residents from 25 districts in Seoul, South Korea (2008)

\begin{tabular}{|c|c|c|c|}
\hline \multirow[b]{2}{*}{ Variables } & \multirow{2}{*}{$\begin{array}{l}\text { Total } \\
\mathbf{N}\end{array}$} & \multicolumn{2}{|c|}{ Prevalence of poor self-rated health } \\
\hline & & $\mathbf{N}(\%)$ & p Value* \\
\hline \multicolumn{4}{|l|}{ Individual level variables ( $\mathrm{N}=7761$ ) } \\
\hline Sex & & & $<0.0001$ \\
\hline Male & 3547 & 599 (16.9) & \\
\hline Female & 4214 & $1021(24.2)$ & \\
\hline Age (years) & & & $<0.0001$ \\
\hline $15-19$ & 536 & $17(3.2)$ & \\
\hline 20-29 & 973 & $26(2.7)$ & \\
\hline $30-39$ & 1577 & $92(5.8)$ & \\
\hline $40-49$ & 1425 & $185(13.0)$ & \\
\hline $50-59$ & 1139 & $242(21.2)$ & \\
\hline $60-69$ & 1130 & $482(42.7)$ & \\
\hline 70 or more & 981 & $576(58.7)$ & \\
\hline Job status & & & $<0.0001$ \\
\hline Employed & 3199 & $293(9.2)$ & \\
\hline Unemployed & 4562 & $1327(29.1)$ & \\
\hline Education level & & & $<0.0001$ \\
\hline Elementary school or less & 1143 & $664(58.1)$ & \\
\hline Junior high school & 703 & $271(38.5)$ & \\
\hline High school & 2483 & $433(17.4)$ & \\
\hline College graduate & 572 & $46(8.0)$ & \\
\hline University graduate & 2516 & $185(7.4)$ & \\
\hline Graduate school or more & 344 & $21(6.1)$ & \\
\hline Marital status & & & 0.151 \\
\hline Married/cohabiting & 5059 & $1031(20.4)$ & \\
\hline Others & 2702 & $589(21.8)$ & \\
\hline Individual perception of district safety & & & $<0.0001$ \\
\hline Safe & 6777 & $1361(20.1)$ & \\
\hline Unsafe & 984 & $259(26.3)$ & \\
\hline \multicolumn{4}{|l|}{ Household level variables $(\mathrm{N}=3665)$} \\
\hline \multicolumn{4}{|l|}{ Household income } \\
\hline $1000000 \mathrm{KRW}$ or less & 770 & & \\
\hline $1010000-2000000 \mathrm{KRW}$ & 772 & & \\
\hline $2010000-3000000 \mathrm{KRW}$ & 656 & & \\
\hline $3010000-4000000 \mathrm{KRW}$ & 510 & & \\
\hline $4010000-5000000 \mathrm{KRW}$ & 345 & & \\
\hline Above $5000000 \mathrm{KRW}$ & 612 & & \\
\hline District level variables $(\mathrm{N}=25)$ & Mean & S.D. & Range \\
\hline District-level perceived safety* & 0.87 & 0.08 & $0.68-0.98$ \\
\hline District-level crime rate & 4.63 & 2.94 & $2.25-16.31$ \\
\hline
\end{tabular}

stronger effects on the fear of crime than larceny and auto theft. Hence, the total crime rate that was used in this research might not be sophisticated enough to examine the association between the prevalence of crime in the district and the residents' health condition. ${ }^{23}$ However, when we conducted a post-hoc analysis using a different measure, ' 5 index crime rate', which includes five major serious crimes (ie, murder, robbery, rape, assault and theft) that has been adopted by the Korean police to indicate violent crime rate, still we could not find association with residents' self-rated health.

Finally, if social and physical resources of neighbourhood are deteriorated or deprived, residents tend to perceive neighbourhood safety more irrespective of the objective neighbourhood crime rate. ${ }^{24}$ The poor quality of the social and physical environment, such as dilapidated houses or having a lack of formal or informal neighbourhood networks, may work as a trigger to make residents perceive their neighbourhood as dangerous. ${ }^{25} 26$

There could be several pathways linking district-level perceived neighbourhood safety to residents' self-rated health. First, poor district-level perceived safety can cause less outdoor physical activities ${ }^{72}$ leading to poor health. Second, poor district-level perceived safety may aggravate social supports which may harm mental and 
Table 2 Association between district-level perceived safety and poor self-rated health among 7761 residents from 25 districts in Seoul, South Korea (2008)

\begin{tabular}{|c|c|c|c|c|c|c|c|c|}
\hline & \multicolumn{2}{|c|}{ Unadjusted } & \multicolumn{6}{|c|}{ Adjusted $†$} \\
\hline & $\overline{\text { OR }}$ & $95 \% \mathrm{Cl}$ & OR & $95 \% \mathrm{Cl}$ & OR & $95 \% \mathrm{Cl}$ & OR & $95 \% \mathrm{Cl}$ \\
\hline $\begin{array}{l}\text { District-level } \\
\text { perceived safety } \ddagger\end{array}$ & $0.83^{\star \star \star}$ & (0.76 to 0.91$)$ & $0.87^{*}$ & (0.78 to 0.97$)$ & $0.86^{\star \star}$ & (0.77 to 0.95$)$ & $0.86^{\star \star}$ & (0.77 to 0.96$)$ \\
\hline $\begin{array}{l}\text { District-level } \\
\text { crime ratefl }\end{array}$ & & & & & 0.97 & (0.93 to 1.01$)$ & 0.97 & (0.93 to 1.01 ) \\
\hline $\begin{array}{l}\text { Individual perception } \\
\text { of district safety }\end{array}$ & & & & & & & 0.82 & (0.65 to 1.04$)$ \\
\hline
\end{tabular}

physical outcomes. ${ }^{28}$ Lastly, poor district-level perceived safety may be a latent stressor causing chronic stress status that could undermine residents' mental health. ${ }^{29}$

Our study has several limitations. First, potential reverse causation is of concern due to its cross-sectional study design, implying that people with poor self-rated health are more likely to perceive their neighbourhood as unsafe. Future studies are required to examine the causal association between district-level perceived safety and health outcomes. Second, this study assessed perceived neighbourhood safety through a single-item measure. This item may not reflect multidimensional aspects of the neighbourhood safety.

Despite these limitations, our study has the strength in that we used representative samples for each operationalised administrative district, which enabled multilevel analysis using a district-level aggregate measure of perceived safety whereas most of the previous studies used individual reporting of perceived safety as an exposure variable. Furthermore, to the best of our knowledge, this is one of the first studies to examine the association between district-level perceived neighbourhood safety and health outcome after adjusting for the district-level crime rate.

In summary, our study showed that district-level perceived safety was associated with residents' poor selfrated health even after controlling for demographic information, SES and district-level crime rate. Our study results evoke the importance of local authorities (or governments) to make efforts toward improving neighbourhood perceived safety to enhance residents' health.

\footnotetext{
Author affiliations

${ }^{1}$ Department of Public Health Sciences, Korea University, Seoul, Republic of Korea

${ }^{2}$ Department of Social and Behavioral Sciences, Harvard School of Public Health, Boston, Massachusetts, USA

${ }^{3}$ Department of Environmental and Occupational Health, The George Washington University School of Public Health and Health Services, Washington DC, USA

${ }^{4}$ Department of Healthcare Management, Korea University, Seoul, Republic of Korea

${ }^{5}$ Department of Economics, Sungkyunkwan University, Seoul,

Republic of Korea
}

${ }^{6}$ Department of Mathematical Sciences, Korea Advanced Institute of Science and Technology, Daejeon, Republic of Korea

${ }^{7}$ Department of Communication, Seoul National University, Seoul, Republic of Korea

${ }^{8}$ Public Health Joint Doctoral Program, San Diego State University \& University of California, San Diego, California, USA

Contributors S-SK coordinated in the design, analysis and in writing the manuscript. JC, KP, YC, SP and JH participated in the design, analysis and in preparing the manuscript. All the authors contributed to read, edit and approve the final draft of the manuscript.

Funding This research received no specific grant from any funding agency in the public, commercial or not-for-profit sectors.

Competing interests None.

Ethics approval San Diego State University.

Provenance and peer review Not commissioned; externally peer reviewed.

Data sharing statement No additional data are available.

Open Access This is an Open Access article distributed in accordance with the Creative Commons Attribution Non Commercial (CC BY-NC 3.0) license, which permits others to distribute, remix, adapt, build upon this work noncommercially, and license their derivative works on different terms, provided the original work is properly cited and the use is non-commercial. See: http:// creativecommons.org/licenses/by-nc/3.0/

\section{REFERENCES}

1. Tseloni A, Mailley J, Farrell G, et al. Exploring the international decline in crime rates. Eur J Criminol 2010;7:375-94.

2. McCall PL, Land KC, Parker KF. Heterogeneity in the rise and decline of city-level homicide rates, 1976-2005: a latent trajectory analysis. Soc Sci Res 2011;40:363-78.

3. Sampson RJ, Raudenbush SW, Earls F. Neighborhoods and violent crime: a multilevel study of collective efficacy. Science 1997;277:918-24.

4. Patterson EB. Poverty, income inequality, and community crime rates. Criminology 1991;29:755-76.

5. Krug EG, Mercy JA, Dahlberg LL, et al. The world report on violence and health. Lancet 2002;360:1083-8.

6. Gary TL, Stark SA, LaVeist TA. Neighborhood characteristics and mental health among African Americans and whites living in a racially integrated urban community. Health Place 2007;13:569-75.

7. Tucker-Seeley RD, Subramanian S, Li Y, et al. Neighborhood safety, socioeconomic status, and physical activity in older adults. Am J Prev Med 2009;37:207-13.

8. Green G, Gilbertson JM, Grimsley MF. Fear of crime and health in residential tower blocks: a case study in Liverpool, UK. Euro J Public Health 2002;12:10-15.

9. Ziersch AM, Baum FE, MacDougall C, et al. Neighbourhood life and social capital: the implications for health. Soc Sci Med 2005;60:71-86. 
10. Raudenbush SW. Hierarchical linear models: applications and data analysis methods. vol 1: Sage, 2002.

11. Kruger DJ, Reischl TM, Gee GC. Neighborhood social conditions mediate the association between physical deterioration and mental health. Am J Community Psychol 2007;40:261-71.

12. Wen M, Hawkley LC, Cacioppo JT. Objective and perceived neighborhood environment, individual SES and psychosocial factors, and self-rated health: an analysis of older adults in Cook County, Illinois. Soc Sci Med 2006;63:2575-90.

13. White M, KasI SV, Zahner GE, et al. Perceived crime in the neighborhood and mental health of women and children. Environ Behav 1987:19:588-613.

14. Idler EL, Benyamini Y. Self-rated health and mortality: a review of twenty-seven community studies. J Health Soc Behav 1997;38:21-37.

15. Supreme Prosecutors' Office Republic Of Korea. Analytical Report on Crimes (2008). 2009.

16. Curry A, Latkin C, Davey-Rothwell M. Pathways to depression: the impact of neighborhood violent crime on inner-city residents in Baltimore, Maryland, USA. Soc Sci Med 2008;67:23-30.

17. Sundquist $\mathrm{K}$, Theobald $\mathrm{H}$, Yang $\mathrm{M}$, et al. Neighborhood violent crime and unemployment increase the risk of coronary heart disease: a multilevel study in an urban setting. Soc Sci Med 2006;62:2061-71.

18. O'Campo P, Xue X, Wang M-C, et al. Neighborhood risk factors for low birthweight in Baltimore: a multilevel analysis. Am J Public Health 1997;87:1113-18.

19. Warr M. Fear of victimization. Public Perspect 1993;5:25-8.
20. Romer D, Jamieson $\mathrm{KH}$, Aday $\mathrm{S}$. Television news and the cultivation of fear of crime. J Commun 2003;53:88-104.

21. Lipschultz JH, Hilt ML. Crime and local television news: dramatic, breaking, and live from the scene. Routledge, 2002.

22. Gerbner G. Cultivation analysis: an overview. Mass Commun Soc 1998;1:175-94.

23. Meier RF, Short JF. Crime as hazard: perceptions of risk and seriousness ${ }^{\star}$. Criminology 1985;23:389-400.

24. Carpiano RM. Toward a neighborhood resource-based theory of social capital for health: can Bourdieu and sociology help? Soc Sci Med 2006;62:165-75.

25. Rodrigues CD. Civil democracy, perceived risk, and insecurity in Brazil: an extension of the systemic social control model. Ann Am Acad Political Soc Sci 2006;605:242-63.

26. Gibson CL, Zhao J, Lovrich NP, et al. Social integration, individual perceptions of collective efficacy, and fear of crime in three cities. Justice Q 2002:19:537-64.

27. Roman CG, Chalfin A. Fear of walking outdoors: a multilevel ecologic analysis of crime and disorder. Am J Prev Med 2008;34:306-12.

28. Kim S-S, Chung Y, Perry MJ, et al. Association between interpersonal trust, reciprocity, and depression in South Korea: a prospective analysis. PLOS ONE 2012;7:e30602.

29. Stockdale SE, Wells KB, Tang L, et al. The importance of social context: neighborhood stressors, stress-buffering mechanisms, and alcohol, drug, and mental health disorders. Soc Sci Med 2007;65:1867-81. 